\title{
Öz-Anlayışın Yordayıcıları Olarak Psikolojik Katılık ve Bilişsel Esneklik ${ }^{1}$
}

\author{
Prof. Dr. M. Engin DENIZ \\ Yıldız Teknik Üniversitesi, Eğitim Fakültesi, Eğitim Bilimleri Bölümleri, İstanbul / Türkiye, \\ edeniz@yildiz.edu.tr, ORCID: 0000-0002-7930-3121
}

\author{
Arş. Gör. Merve GÜNDÜZ* \\ İstanbul Aydın Üniversitesi, Fen-Edebiyat Fakültesi, Psikoloji Bölümü, İstanbul / Türkiye, \\ mervegunduz@aydin.edu.tr, ORCID: 0000-0003-4261-4820
}

\section{$\ddot{O}_{z}$}

$\mathrm{Bu}$ araştırma, üniversite öğrencilerinin psikolojik katılık ve bilişsel esneklik değişkenlerinin öz-anlayış düzeylerini ne denli yordadığını ve bazı kişisel değişkenlere ve algılanan anne-baba tutumlarına göre öğrencilerin öz-anlayıș düzeylerinin anlamlı farklılık gösterip göstermediğini incelemek amacıyla yapılan betimsel türde bir çalışmadır. Araştırma örneklemini İstanbul Aydın Üniversitesi, Fen-Edebiyat Fakültesi'ne bağlı farklı bölümlerde birinci ve dördüncü sınıfa devam eden 246 kadın, 77 erkek olmak üzere toplam 323 üniversite öğrencisi oluşturmaktadır. Araştırmada veri toplama araçları olarak Türkçe uyarlamaları ve geçerlilik ve güvenirlik çalışmaları yapılmış olan Öz-Anlayış Ölçeği, Kabul ve Eylem Formu-II, Bilişsel Esneklik Envanteri ve araştırmacılar tarafindan hazırlanan kişisel bilgi formu kullanılmıştır. Verilerin analizinde Pearson momentler çarpımı korelasyon analizi, regresyon analizi, $t$ Testi,

\footnotetext{
${ }^{1}$ Bu çalışma, 27-29 Haziran 2019 tarihinde gerçekleşen V. Turkcess Eğitim ve Sosyal Bilimler Kongresi’nde sözlü bildiri olarak sunulmuştur.

* Sorumlu Yazar. Tel: $4441428 / 20408$

Makale Tarih Bilgisi. Gönderim: 24.07.2019, Kabûl: 10.03.2020, Erken Görünüm: 03.05.2021, Basım: Haziran, 2021

(C) 2021. Kalem Eğitim ve Sağlık Hizmetleri Vakfı. Bütün Hakları Saklıdır. ISSN: 2146-5606, e-ISSN: 2687-6574.
} 
Kruskal-Wallis H ve Mann Whitney-U Testi kullanılmıştır. Araştırmanın sonucunda öz-anlayış ile psikolojik katılık arasında yüksek düzeyde negatif yönlü bir ilişki, özanlayış ile bilişsel esneklik arasında orta düzeyde pozitif yönlü bir ilişki bulunmuştur. Ayrıca psikolojik katılık ve bilişsel esneklik değişkenlerinin öz-anlayışı anlamlı derecede yordadığı saptanmıştır. Sınıf düzeyi ve algılanan anne-baba tutumuna göre özanlayış düzeyi anlamlı farklılık gösterirken, cinsiyet değişkeni açısından anlamlı bir farklılık bulunmamıştır. Dördüncü sınıfa devam eden öğrencilerin birinci sınıfa devam eden öğrencilere oranla öz-anlayış düzeyleri anlamlı derecede yüksek bulunmuştur. Demokratik anne-baba tutumuna sahip öğrencilerin öz-anlayış düzeyleri ile ilgisiz, koruyucu ve tutarsız anne-baba tutumuna sahip öğrencilerin öz-anlayış düzeyleri arasında anlamlı farklılıklar bulunmuştur. Bulgular alanyazında bağlı kalarak tartışılmış ve önerilerde bulunulmuştur.

Anahtar Kelimeler: Öz-Anlayış; Psikolojik katılık; Bilişsel esneklik; Üniversite öğrencileri; Algilanan ebeveyn tutumları.

\title{
Psychological Inflexibility and Cognitive
}

\section{Flexbility as Predictors of Self-Compassion}

\begin{abstract}
This research is a descriptive study conducted to examine the extent to which the variables of psychological inflexibility and cognitive flexibility predict the self-compassion levels of university students and whether students' self-compassion levels show significant differences according to some personal variables and perceived parental attitudes. The sample of the study consists of 323 university students (246 female, 77 male) attending first and fourth grades in different departments of the Faculty of Arts and Sciences of Istanbul Aydin University. In the study, "Self-Compassion Scale", "Acceptance and Action Form-II" and "Cognitive Flexibility Inventory" and "Personal Information Form" were used to measure data. Pearson product-moment correlation analysis, regression analysis, $t$ Test, Kruskal-Wallis H and Mann Whitney-U were used to analyze the data. According the results of the study, there was a high negative correlation between self-compassion and psychological inflexibility, and a moderate positive relationship between selfcompassion and cognitive flexibility. Also, it was found that psychological inflexibility and cognitive flexibility significantly predicted self-compassion. While the level of self-compassion showed a significant difference according to grade level and perceived parental attitude, no significant difference was found in terms of gender. The level of self-compassion of the students attending the fourth grade was found to be significantly higher than the students attending the first grade. According to perceived parental attitudes, significant differences were
\end{abstract}


found between students' self-compassion levels. The findings were discussed in accordance with the literature and suggestions were made.

Keywords: Self-compassion; Psychological inflexibility; Cognitive flexibility; University students; Perceived parental attitude.

\section{Extended Summary}

\section{Purpose}

It is inevitable for individuals to face sadness, pain, failure, and challenging experiences in their lives. Self-compassion is one of the important concepts that are considered as one of the healthy attitudes of the person when exposed to these negative experiences. Self-compassion includes the desire to be open to them rather than to avoid or stay away from painful experiences, and the desire to relieve pain and to heal himself kindly. In addition, selfcompassion means that the person approaches his/her pain, inadequacies and failures with a non-judgmental understanding and accepts his/her experiences as a part of human life (Neff, 2003a).

In the literature, it was found that self-compassion is negatively correlated with psychological inflexibility and positively correlated with cognitive flexibility (Seligowski, Miron and Orcutt 2015; Martin, Staggers and Anderson, 2011). Psychological inflexibility means being self-judgmental, avoiding internal experiences and giving more importance to psychological reactions than values or meaningful activities (Bond et al., 2011). Cognitive flexibility is considered as the ability to adapt the individual's cognitions to changing environmental conditions (Dennis and Vander Wal, 2010).

However, the researches that examine the relationships between selfcompassion, psychological inflexibility and cognitive flexibility are quite limited and in Turkey, there is no research found that investigates the relationships between these variables. In addition, a study examining the predictive effect of these two variables on self-compassion was not found in the literature. The aim of this study is to examine the extent to which the variables of psychological inflexibility and cognitive flexibility predict the self-compassion levels of university students and whether students' self-compassion levels show significant differences according to some personal variables and perceived parental attitudes.

\section{Method}

The sample of the study consists of 323 university students ( 246 female, 77 male) attending first and fourth grades in different departments of the 
Faculty of Arts and Sciences of Istanbul Aydın University. The measurement tools used to obtain data are "Self-Compassion Scale (Deniz, Kesici and Sümer, 2008)", "Acceptance and Action Form-II (Yavuz et al., 2016)" and "Cognitive Flexibility Inventory (Gülüm and Dağ, 2012)" and "Personal Information Form". Pearson product-moment correlation analysis, regression analysis, $t$ Test, Kruskal-Wallis $\mathrm{H}$ and Mann Whitney-U were used to analyze the data.

\section{Results}

Pearson Product Moment Correlation Analysis was performed to determine the relationship between self-compassion, psychological inflexibility and cognitive flexibility levels of university students. A significant positive correlation was found between self-compassion and psychological inflexibility $(\mathrm{r}=-.701, p<0.01)$. On the other hand, a significant positive correlation was found between self-compassion and cognitive flexibility $(\mathrm{r}=.589, p<0.01)$.

Regression analysis was conducted to determine whether or not the variable of psychological inflexibility predict self-compassion. The variable of psychological inflexibility explains $49.2 \%$ of the total variance in self-compassion levels of university students. Psychological inflexibility predicted self-compassion negatively $(\beta=-.701, p<0.01)$.

Another regression analysis was conducted to determine whether or not the variable of cognitive flexibility predict self-compassion. The variable of cognitive flexibility explains $34.7 \%$ of the total variance in self-compassion levels of university students. Cognitive flexibility predicted self-compassion positively $(\beta=.589, p<0.01)$.

The independent group $t$ Test was used to determine whether the university students' self-compassion levels differed according to grade levels and gender. While the level of self-compassion differed significantly according to grade level $(\mathrm{t}=-1.155, p<0.05)$, no significant difference was found in terms of gender $(\mathrm{t}=-1.155, p>0.05)$. Self-compassion scores $(X=75.2169)$ of students attending fourth grade were found to be significantly higher than the self-understanding scores $(X=70.2357)$ of students attending the first grade $(p<0.05)$.

Kruskal-Wallis $\mathrm{H}$ was used to determine whether university students' self-compassion levels differ according to perceived parental attitudes. According to perceived parental attitudes, significant differences were found 
between students' self-compassion levels. $\left(\mathrm{X}^{2}=19.66\right.$; $\left.\mathrm{sd}=4 ; p<0.05\right)$. Mann Whitney-U Test was used to determine the source of differentiation. The selfcompassion mean rank of the students who perceived the parental attitude as democratic were found to be significantly higher than the self-compassion mean rank of the students who perceived the parental attitude as irrelevant, protective and inconsistent.

\section{Discussion and Conclusion}

As a result of the study, a significant negative relationship was found between self-compassion and psychological inflexibility and it was found that psychological inflexibility predicted self-compassion negatively. The result is consistent with a similar study in the literature (Seligowski et al., 2015). Because self-compassion is considered as openness to internal experiences without judgment (Neff, 2003a) and because individuals with self-compassion are less likely to suppress unwanted thoughts and emotions (Leary, Tate, Adams, Allen and Hancock, 2007), it is thought that there will be a negative relationship between self-compassion and psychological inflexibility (Seligowski et al., 2015).

According to a result of the study, a significant positive relationship was found between self-compassion and cognitive flexibility, and it was found that cognitive flexibility predicted self-compassion positively. Martin, Staggers and Anderson (2011) found that there is a positive significant relationship between cognitive flexibility and self-compassion. Individuals with cognitive flexibility may be expected to have higher self-compassion, because of having more balanced and adaptive thoughts, producing alternatives, and seeing challenging situations more manageable (Gülüm and Dağ, 2012).

While the level of self-compassion of university students showed a significant difference according to their grade levels, it was concluded that there was no significant difference according to gender. In the literature, similar studies with the findings of our research (Dilmaç, Deniz and Deniz, 2009; Neff and Pommier, 2013; Özyeşil, 2001), as well as different studies (Çırpan, 2016; Nazik and Arslan, 2011; Neff, 2003b; Yarnell et al., 2015). There are studies in the literature that are similar to the findings of our research (Dilmaç et al., 2009; Özyeşil, 2001; Neff and Pommier, 2013) and on the other hand, there are also studies that are different to the findings of our research (Çırpan, 2016; Nazik and Arslan, 2011; Neff, 2003b; Yarnell et al., 2015). It is seen in the 
literature that the results reached in terms of grade level and gender are not consistent.

As another result of the study, it was found that the self-compassion scores of students with democratic parental attitude were higher than those with irrelevant, protective and inconsistent parental attitude. Similar studies in the literature support the findings of this study (Çırpan, 2016; Özyeşil, 2001; Y1lmaz and Kesici, 2014). Due to the fact that family environments with democratic parental attitudes have safe and supportive features, such environment also has characteristics that enhance self-compassion (Neff and McGhee, 2010)

Since the development of self-compassion will also affect psychological health positively, the necessity of developing self-compassion has been emphasized (Sümer, 2008). Based on the findings of the study, studies can be conducted to reduce psychological inflexibility and increase cognitive flexibility in the programs to be prepared to increase and improve self-compassion levels of university students. Based on the positive relationship between democratic parental attitude and self-compassion, programs can also be prepared for parents to have a democratic parental attitude. In addition, since there are no other studies related to the variables examined in this study, new studies can be made in terms of generalizability of the results.

\section{Giriş}

Bireylerin hayatlarında üzücü, acı veren, başarısızlık yaşatan, zorlayıcı olaylarla karşı karşıya gelmesi kaçınılmazdır. Bu olumsuz deneyimlere maruz kaldığında kişinin kendine karşı sergilediği sağlıklı tutumlardan biri olarak ele alınan ve psikolojik sağlığı geliştirdiği kabul edilen önemli kavramlardan biri öz-anlayıştır. Öz-anlayış, kişinin acı veren yaşantılarından kaçınmak veya uzak durmak yerine onlara karşı açık olmasını ve acıyı hafifletme ve kendini nezaketle iyileştirmeye yönelik arzuya sahip olmasını içermektedir. Ayrıca öz-anlayış, kişinin acısına, yetersizliklerine ve başarısızlıklarına karşı yargılayıcı olmayan bir anlayışla yaklaşması ve yaşadı ğı deneyimleri insan hayatının bir parçası olarak kabul etmesi anlamına da gelmektedir (Neff, 2003a).

Acı veren yaşantılar ya da kişisel başarısızlıklar gibi olumsuz durumlarla karşı karşıya kalındığında öz-anlayışın, öz-nezaket (self-kindness), ortak insanlık deneyimi (common humanity) ve bilinçli farkındalık (mindfulness) olmak üzere üç temel bileşeni gerekli kıldığı belirtilmiştir. Öz-nezaket, kişinin 
kendisine karşı sert bir yargılama ve öz-eleştiri yerine nezaket ve anlayışla yaklaşmasıdır. Ortak insanlık deneyimi, kişinin deneyimlerini ayıran ve izole eden nitelikte görmesi yerine tüm insanları yaşadığı deneyimlerin bir parçası olarak görmesidir. Bilinçli farkındalık ise, acı verici düşünce ve duygularla aşırı özdeşleşmek yerine onlara dengeli bir farkındalık içinde yaklaşmaktır. $\mathrm{Bu}$ bileşenlerin kavramsal yönden farklı olmasına rağmen, birbirlerini karş1lıklı olarak geliştirecek ve etkileyecek şekilde etkileşim halinde oldukları belirtilmiştir (Neff, 2003a). Öz-anlayış kavramı, bireyin bilinçli olarak hislerinin farkında olmasına, bu farkındalığın ve yaşadığı olumsuz deneyimlerin insanlığın bir parçası olduğu düşüncesinin kabulü ile acı veren düşünce ve duyguları yok saymak yerine onları nezaketle, anlayışla karşılamasına vurgu yapmaktadır (Neff, 2003a; Neff, 2003b).

Öz-anlayış doğrudan merhamet hissi ve başkaları için endişe ile ilişkili olduğu için bencillik ya da benmerkezcilik içermemekte ve başkalarının ihtiyaçlarına göre kişisel ihtiyaçlarına öncelik verme anlamına gelmemektedir (Neff, 2003b). Öz-anlayış kavramı anlayış kavramından türetilmiştir ve anlayış, başkalarının acılarına karşı farkında ve duyarlı olmayı, bu acılara karşı bağlantısız kalmamayı, başkalarına karşı şefkatli olmayı, onların acılarını hafifletme arzusunu taşımayı ve başarısız olan, hata yapan kişileri yargılamadan anlamayı da kapsamaktadır (Deniz, Kesici ve Sümer, 2008). Ayrıca öz-anlayış, kendine acımadan farklıdır. Kendine acıma, kişinin kendi fiziksel ya da zihinsel acı, sıkıntı ya da mutsuzluğundan kaynaklanan sempatik, içten bir üzüntü olarak tanımlanmaktadır. Kendine acıma duygusuna genellikle üzüntü ve kayıp duyguları ve artan adaletsizlik duygusu ile eşlik eder. Kendine karşı acıma hisseden kişi, benzer bir kayıp ya da kader yaşamayan diğer kişilere karşı kıskançlık/çekememezlik duygusu hissedebilirler (Stöber, 2003). Öte yandan öz anlayış süreci, kendine acımanın tersine, bireyin başkalarının ve kendinin ilgili deneyimlerini fark etmeye olanak tanıyan üst-bilişsel faaliyetlerde bulunmasını gerektirir. Bu süreç, sadece kendiyle ilgilenme ve kendiyle fazla özdeşleşme döngüsünü kırma eğilimindedir ve böylece diğerlerinden olumsuz deneyimler açısından ayrılmanın benmerkezci hislerini azaltırken, karşılıklı bağlılık hislerini artırır. Aynı zamanda bu süreçte birey, yaşadığı 1stırabın boyutunu daha net şekilde görebilmek için, kişisel deneyimlere daha büyük bir bakış açısıyla yaklaşma eğilimindedir (Neff, 2003b).

Öz-anlayışı gelişen kişilerin kendileriyle ilgili olumlu düşüncelerinin geliştiği, olumsuz düşüncelerinin etkisinin azaldığ 1 ve kişilerin maruz kaldığ 1 
olumsuz yaşantılardan tecrübe kazandığı belirtilmiştir (Deniz ve ark., 2008). Öz-anlayışın olumlu zihinsel sağlık ve uyum sağlayıcı işleyişle anlamlı şekilde ilişkili olduğu söylenmiştir (Neff, 2004). Deniz ve arkadaşları (2008) tarafından yapılan araştırmada da öz-anlayış ile yaşam doyumu ve olumlu duygulanım arasında pozitif yönlü, olumsuz duygulanım ile negatif yönlü anlamlı bir ilişki bulunmuştur. Yapılan farklı araştırmalarda da öz-anlayış düzeyi yüksek olan kişiler düşük olanlara göre daha mutlu hissettiklerini bildirmişlerdir (Hollis-Walker ve Colosimo, 2011; Neff, Kirkpatrick ve Rude, 2007; Shapira ve Mongrain, 2010; Smeets, Neff, Alberts ve Peters, 2014).

Sümer (2008) tarafından yapılan çalışmada üniversite öğrencilerinin öz-anlayış düzeyleri ile depresyon, anksiyete ve stres düzeyleri arasındaki ilişki araştırılmıştır. Araştırmanın sonucunda öz-anlayış düzeyi düşük ve orta olan kişilerin, öz-anlayış düzeyi yüksek olanlara göre depresyon, anksiyete ve stres düzeyleri daha yüksek olduğu saptanmıştır. Neff ve arkadaşları (2007) tarafindan yapılan çalışmalarda öz-anlayışın anksiyeteye karşı koruyucu olduğu ve öz-anlayış düzeyindeki artışların psikolojik iyi oluş düzeyindeki artışlarla ilişkili olduğu bulunmuştur. Ayrıca öz-anlayışı yüksek bireylerin olumlu bilişsel yeniden yapılandırmaya büyük ölçüde meyilli olduklarını söylenmiştir (Allen ve Leary, 2010).

Öz-anlayışın psikolojik esneklik ile olumlu yönde ilişkili olduğu belirtilmiştir (Neff ve Tirch, 2013). Öte yandan psikolojik esnekliğin karşıtı olan psikolojik katılığın ise öz-anlayış ile olumsuz yönde ilişkili olduğu (Seligowski, Miron ve Orcutt, 2015) ve psikolojik sağlığın olumsuz yönde yordayıc1sı olduğu bulunmuştur (Woodruff ve ark., 2014). Psikolojik katılık, kendine karşı yargılayıcı olma, içsel deneyimlerden kaçınma ve psikolojik tepkilere değerler veya anlamlı faaliyetlerden daha fazla önem verme anlamına gelmektedir (Bond ve ark., 2011). Psikolojik katılık ayrıca Kabul ve Kararlılık Terapisi'nde psikopatoloji modeli olarak kabul edilmekte ve belirli bir durumda bireyin davranış dağarcığının darlık düzeyini ifade etmektedir. Bilişsel birleşme, an ile temasın kaybolması, geçmiş ve geleceğe bağlanma, yaşantısal kaçınma, değerlerden uzaklaşma, kavramlaştırılmış benliğe bağlanma ve kaçınma/ kaçma ve dürtüsellik olmak üzere altı boyuttan oluştuğu belirtilmiştir (Yavuz, 2015). Öz-anlayışın içsel deneyimlere yargılayıcı olmadan açık olmayı ifade etmesi (Neff, 2003a) ve öz-anlayışı olan bireylerin istenmeyen düşünce ve duyguları bastırma olasılığının daha düşük olması (Leary, Tate, Adams, Allen ve Hancock, 2007) sebebiyle, öz-anlayış ile psikolojik katılık 
arasında olumsuz yönde bir ilişkinin bekleneceği belirtilmiştir (Seligowski ve ark., 2015). Yapılan bir araştırmada öz-anlayış ile psikolojik katılık arasında olumsuz yönde anlamlı ilişki olduğu saptanmıştır (Seligowski ve ark., 2015).

Öz-anlayış ile olumlu yönde ilişkisi bulunan değişkenlerden bir diğeri de bilişsel esnekliktir (Martin, Staggers ve Anderson, 2011). Bilişsel esneklik, bireyin sahip olduğu bilişleri değişen çevresel koşullara adapte edebilme becerisi olarak ele alınmaktadır (Dennis ve Vander-Wal, 2010). Bu beceriye sahip kişiler, zorlayıcı ve uyumsuz düşünceler yerine daha dengeli ve uyumlu düşüncelere sahip olabilmekte, alternatifler üretebilmekte ve zorlayıcı durumları daha başa çıkılabilir görmektedir (Gülüm ve Dağ, 2012). Bilişsel esneklik, aynı anda birden fazla bilgiyi işlemden geçirmeyi, birden fazla fikir üretmeyi, alternatifleri düşünmeyi ve belirli bir duruma veya bağlama uyum sağlamak için planları değiştirmeyi veya düzenlemeyi içerir (Anderson, 2002; Eslinger ve Grattan, 1993). Martin ve arkadaşları (2011) yapmış oldukları çalışmalarında bilişsel esneklik ile öz-anlayış arasında olumlu yönde anlamlı ilişki olduğunu saptamıştır.

Yapılan bilimsel araştırmalarda görüldüğü gibi öz-anlayış ile psikolojik katılık arasında olumsuz ilişkinin varlığı bulunurken, bilişsel esneklik ile arasinda olumlu yönde ilişki olduğundan söz edilmiştir (Seligowski ve ark., 2015; Martin ve ark., 2011). Ancak bu araştırmaların oldukça kısıtlı olduğu görülmüş ve Türkiye'de yapılan araştırmalarda öz-anlayış ile bahsi geçen değişkenlerin arasındaki ilişkiye dair yapılan bir araştırmaya rastlanılmamıştır. Ayrıca alanyazında bahsi geçen iki değişkenin öz-anlayış üzerindeki etkisini birlikte inceleyen bir araştırmaya da rastlanılmamıştır. Bu çalışma ile öz-anlayışı etkileyen farklı değişkenlerin belirlenebileceği ve ilgili değişkenlerin etkileri göz önüne alınarak psikolojik sağlıkla da ilişkili olan öz-anlayışı artırmaya yönelik geliştirilebilecek programlar için alanda çalışan uygulayıcı ve araştırmacılara katkı sunulacağı düşünülmektedir. Bu çalışmanın amacı, üniversite öğrencilerinin psikolojik katılık ve bilişsel esneklik değişkenlerinin özanlayış düzeylerini ne denli yordadığını ve bazı kişisel değişkenlere ve algılanan anne-baba tutumlarına göre öğrencilerin öz-anlayış düzeylerinin anlamlı farklılık gösterip göstermediğini incelemektir.

\section{Yöntem}

\section{Araştırma Modeli ve Çalışma Grubu}

$\mathrm{Bu}$ araştırma genel tarama modeline uygun olarak yürütülmüş̧ür. Araştırmanın örneklemi İstanbul Aydın Üniversitesi, Fen-Edebiyat Fakültesi'ne 
bağlı çeşitli bölümlerde öğrenim gören 246'sı kadın, 77'si erkek olmak üzere toplam 323 öğrenciden oluşmaktadır. Örneklem, kolayda/uygun örnekleme (convenience sampling) yöntemi ile seçilmiştir. Kolayda/uygun örnekleme, araştırmacının kolayca ulaşabileceği bir örneklemden verileri elde etmesini ifade etmektedir (Büyüköztürk, Kılıç-Çakmak, Akgün, Karadeniz ve Demirel, 2015). Araştırmanın bağımlı değişkeni öz-anlayış iken; bağımsız değişkenleri psikolojik katılık, bilişsel esneklik, cinsiyet, sınıf düzeyi ve algılanan annebaba tutumudur.

\section{Veri Toplama Araçları Öz-Anlayış Ölçeği}

Orijinali 26 madde ve 6 alt ölçekten oluşan Öz-Anlayış Ölçeği (SelfCompassion Scale) Neff (2003b) tarafından geliştirilmiştir. Ölçek 5'li likert tipi (" $1=$ Hemen hemen hiçbir zaman" ve " $5=$ Hemen hemen her zaman") derecelendirilmektedir. Ölçeğin Türkçe güvenirlik ve geçerlik çalışması Deniz ve arkadaşları (2008) tarafından yapılmıştır. Türkçe uyarlaması yapılan ölçeğin orijinalinden farklı olarak tek boyutlu bir yapı gösterdiği bulunmuş ve madde toplam korelasyonunda .30 altında kalan 2 madde ölçekten çıkarılarak toplamda 24 maddelik bir ölçek elde edilmiştir. İç tutarlılık katsayısının .89 ve test-tekrar test korelasyonunun .83 olduğu saptanmıştır. Öz-anlayış ölçeğinin (ÖZAN) ölçüt-bağıntılı geçerliğinde ise, ÖZAN ile yaşam doyumu arasında $\mathrm{r}=.45$; benlik saygisı arasında $\mathrm{r}=.62$; pozitif duygu arasinda $\mathrm{r}=.41 \mathrm{ve}$ negatif duygu arasında $\mathrm{r}=-.48$ düzeyinde ilişkiler bulunmuştur (Deniz ve ark., 2008). Öz-Anlayış Ölçeği'nin bu araştırma için iç tutarlılık katsayısı .75 olarak hesaplanmıştır.

\section{Kabul ve Eylem Formu-II}

Kabul ve Eylem Formu-II'nun (Acceptanceand Action Questionnaire (AAQ II)) orijinali Bond ve arkadaşları (2011) tarafindan psikolojik katılık düzeyini ölçmek amaciyla geliştirilmiştir. Ölçek 7'li likert tipi (" $1=$ Hiçbir zaman doğru değil" ve "7=Daima doğru”) derecelendirilmektedir. Ölçeğin Türkçe geçerlik ve güvenirlik çalışmaları Yavuz ve arkadaşları (2016) tarafından yapılmıştır. Ölçek varyansın \%61.8'ini açıklayan bir faktörden oluşmaktadır ve ölçeğin iç tutarlık katsayısı .90 olarak hesaplanmıştır. Test-tekrar test güvenirliği . 85 olarak hesaplanmış ve Kabul ve Eylem Formu-II ile Beck depresyon ölçeği arasında .63; ruminatif düşünme biçimi ölçeği ile arasında .53 düzeyinde bir ilişki saptanmıştır. Ölçekten alınan yüksek puanlar psikolojik katılık düzeyinin yüksek olduğunu göstermektedir (Yavuz ve ark., 2016). 
Kabul ve Eylem Formu-II'nun bu araştırma için iç tutarlılık katsayısı .88 olarak hesaplanmıştır.

\section{Bilişsel Esneklik Envanteri}

Bilişsel Esneklik Envanteri, Dennis ve Vander Wal (2010) tarafindan kişilerin zorlayıcı durumlarla karşı karşıya kaldıklarında alternatif, uyumlu, uygun ve dengeli düşünceler üretebilme becerisini ölçmek amaciyla geliştirilmiş ve bilişsel esneklik kavramını ölçmek için hazırlanmıştır. Ölçek 5'li likert tipi derecelendirilmekte ve 20 maddeden oluşmaktadır. Alternatifler ve kontrol olmak üzere iki alt boyutu bulunmaktadır. Ölçeğin Türkçe geçerlik ve güvenirlik çalışmaları Gülüm ve Dağ (2012) tarafindan gerçekleştirilmiştir. Uyarlama çalışmasında orijinal ölçekteki iki faktörlü yap1 doğrulanmıştır. Toplam puan için Cronbach Alfa değeri 0.90, alternatifler alt boyutu için 0.89 ve kontrol alt boyutu için 0.85 olarak bulunmuştur. Ölçekten alınan puan arttıkça, bilişsel esnekliğin arttığı kabul edilmektedir (Gülüm ve Dağ, 2012). Bilişsel Esneklik Envanteri'nin bu araştırma için iç tutarlılık katsayısı .92 olarak hesaplanmıştır.

\section{Kişisel Bilgi Formu}

Araştırmacılar tarafından hazırlanan formda katılımcıların cinsiyeti, yaşı, bölümü, sınıf düzeyi ve algıladıkları anne-baba tutumuna yönelik 5 tane soru bulunmaktadir.

\section{Verilerin Toplanması ve Analizi}

Araştırmada öğrencilerin öz-anlayış, psikolojik katılık ve bilişsel esneklik düzeyleri arasındaki ilişkiyi belirlemek amacıyla Pearson momentler çarpımı korelasyon analizi kullanılmıştır. Psikolojik katılık ve bilişsel esneklik değişkenlerinin öz-anlayış düzeylerini ne denli yordadığını belirlemek için regresyon analizinden yararlanılmıştır. Cinsiyet ve sınıf değişkenlerine göre öz-anlayış düzeylerinin farklılaşıp farklılaşmadığını belirlemek için $t$ Testi; algılanan anne baba tutumuna göre öz-anlayış düzeylerinin farklılaşıp farklılaşmadığını belirlemek için Kruskal-Wallis H ve farklılı̆̆ın nereden kaynaklandığını belirlemek için de Mann-Whitney-U analizleri kullanılmıştır.

\section{Bulgular}

$\mathrm{Bu}$ bölümde araştırmanın amacı doğrultusunda toplanan verilerin istatistiksel analizleri sonucu elde elden bulgulara yer verilmiştir. Öz-anlayış, psikolojik katılık ve bilişsel esneklik değişkenlerinde verilerin normal dağılım gösterdiği bulunarak ve çarpıklık ve basıklık değerleri incelenmiştir. Çarpıklık 
ve basıklık değerleri sırasıyla öz-anlayış için -.07 ve -.09; psikolojik katılık için .55 ve .35 ve bilişsel esneklik için -.41 ve -. 16 olarak hesaplanmıştır. Çarpıklık ve basıklık katsayılarının $-1,+1$ sınırları içinde bulunması dağılımın normalden sapmadığını göstermektedir (Büyüköztürk, 2005).

Üniversite öğrencilerinin öz-anlayış, psikolojik katılık ve bilişsel esneklik düzeyleri arasındaki ilişkiyi belirlemek üzere Pearson Çarpım Moment Korelasyon Analizi yapılmıştır. Aşağıdaki tabloda ilgili analiz sonuçları yer almaktadir (Tablo 1).

Tablo 1. Öz-Anlayış, Psikolojik Katılık ve Bilişsel Esneklik Değişkenlerinin Arasındaki İlişkiyi Belirlemek Üzere Yapılan Pearson Çarpım Moment Korelasyon Analizi Sonuçları

\begin{tabular}{lccc}
\hline Değişken & $\mathbf{1}$ & $\mathbf{2}$ & $\mathbf{3}$ \\
\hline 1.Öz-Anlayıș & - & $-.701^{* *}$ & $.589^{* *}$ \\
2.Psikolojik Katılık & $-.701^{* *}$ & - & $-.487^{* *}$ \\
3.Bilişsel Esneklik & $.589^{* *}$ & $-.487^{* *}$ & - \\
\hline${ }^{* *} p<0.01$ & & &
\end{tabular}

Tablo 1 incelendiğinde öz-anlayış ile psikolojik katılık değişkenleri arasında yüksek düzeyde olumlu yönde anlamlı ilişki bulunmuştur ( $\mathrm{r}=-.701$, $p<0.01)$. Öte yandan, öz-anlayış ile bilişsel esneklik değişkenleri arasında ise orta düzeyde olumlu yönde anlamlı bir ilişki olduğu saptanmıştır ( $\mathrm{r}=.589$, $p<0.01)$. Bu sonuçlar üniversite öğrencilerinin psikolojik katılık düzeyleri arttıkça öz-anlayış düzeylerinin azaldığını, bilişsel esneklik düzeyleri arttıkça da öz-anlayış düzeylerinin arttığını göstermektedir.

Psikolojik katılık değişkeninin öz-anlayışı yordayıp yordamadığını belirlemek için regresyon analizi yapılmıştır. Aşağıdaki tabloda ilgili analiz sonuçları yer almaktadır (Tablo 2).

Tablo 2. Psikolojik Katılık Değişkeninin Öz-Anlayışı Yordayıp Yordamadığını Belirlemek Üzere Yapılan Regresyon Analizi Sonuçları

\begin{tabular}{lccccccc}
\hline $\begin{array}{l}\text { Bağımlı Değişken: } \\
\text { Öz-Anlayış }\end{array}$ & $\mathbf{R}$ & $\mathbf{R}^{\mathbf{2}}$ & Uyarlanmış R $^{2}$ & $\mathbf{B}$ & $\boldsymbol{\beta}$ & $\mathbf{t}$ & $\boldsymbol{p}$ \\
\hline $\begin{array}{l}\text { Sabit } \\
\text { Psikolojik Katılık }\end{array}$ & $.701^{\mathrm{a}}$ & .492 & .490 & 10 & & 58.65 & .000 \\
\hline
\end{tabular}

Tablo 2 incelendiğinde, psikolojik katılık değişkeninin öz-anlayışı anlamlı şekilde yordadığı görülmektedir $(\mathrm{R}=.701, p<0.01)$. Psikolojik katılık değişkeni üniversite öğrencilerinin öz-anlayış düzeylerindeki toplam varyansın \%49.2'sini açıklamaktadır. Psikolojik katılık, öz anlayışı negatif yönde anlamlı olarak yordamaktadır $(\beta=-.701, p<0.01)$. 
Bilişsel esneklik değişkeninin öz-anlayışı yordayıp yordamadığını belirlemek için regresyon analizi yapılmıştır. Aşağıdaki tablo ilgili analiz sonuçları yer almaktadır (Tablo 3).

Tablo 3. Bilişsel Esneklik Değişkeninin Öz-Anlayışı Yordayıp Yordamadığını Belirlemek Üzere Yapılan Regresyon Analizi Sonuçları

\begin{tabular}{lccccccc}
\hline $\begin{array}{l}\text { Bağımlı Değişken: } \\
\text { Öz-Anlayış }\end{array}$ & $\mathbf{R}$ & $\mathbf{R}^{\mathbf{2}}$ & Uyarlanmış $^{2}$ & $\mathbf{B}$ & $\boldsymbol{\beta}$ & $\mathbf{t}$ & $\boldsymbol{p}$ \\
\hline Sabit & $.589^{\mathrm{a}}$ & .34 & .345 & 19. & & 4.59 & .000 \\
Bilişsel Esneklik & & & & .71 & .59 & 13.05 & .000 \\
\hline
\end{tabular}

Tablo 3 incelendiğinde, bilişsel esneklik değişkeninin öz-anlayışı anlamlı şekilde yordadığı görülmektedir $(\mathrm{R}=.589, p<0.01)$. Bilişsel esneklik değişkeni üniversite öğrencilerinin öz-anlayış düzeylerindeki toplam varyansın \%34.7'sini açıklamaktadır. Bilişsel esneklik, öz anlayışı pozitif yönde anlamlı olarak yordamaktadır $(\beta=.59, p<0.01)$.

Üniversite öğrencilerinin öz-anlayış düzeylerinin sınıf düzeylerine ve cinsiyete göre farklılaşıp farklılaşmadığını belirlemek için bağımsız grup $t$ Testi yapılmıştır. İlgili testin sonuçları aşağıdaki tabloda yer almaktadır (Tablo 4).

Tablo 4. Öz-Anlayış Düzeylerinin Sınıf ve Cinsiyet Değişkenlerine Göre Farklılaşıp Farklılaşmadığını Belirlemek Üzere Yapılan $t$ Testi Sonuçları

\begin{tabular}{llccccc}
\hline Bağımlı Değişken & Gruplar & N & Ortalama & ss & t & $\boldsymbol{p}$ \\
\hline Öz-Anlayış & Kadın & 246 & 72.19 & 18.35 & -1.15 & .249 \\
& Erkek & 77 & 74.74 & 11.16 & & \\
\hline Öz-Anlayış & Birinci Sınıf & 157 & 70.23 & 17.57 & -2.66 & .008 \\
& Dördüncü Sınıf & 166 & 75.22 & 15.99 & & \\
\hline
\end{tabular}

$\overline{{ }^{*} p<0.05}$

Tablo 4 incelendiğinde, üniversite öğrencilerinin öz-anlayış düzeylerinin öğrencinin cinsiyetine göre anlamlı bir farkl1lık gösterip göstermediğini belirlemek amacıyla gerçekleştirilen bağımsız grup $t$ Testi sonucunda, grupların aritmetik ortalamaları arasındaki fark istatistiksel olarak anlamlı bulunmamıştır ( $\mathrm{t}=-1.15, p>0.05)$. Öğrencilerinin öz-anlayış düzeylerinin öğrencinin sınıf düzeyine göre anlamlı bir farklılık gösterip göstermediğini belirlemek amacıyla gerçekleştirilen bağımsız grup $t$ Testi sonucunda ise grupların aritmetik ortalamaları arasındaki fark istatistiksel olarak anlamlı bulunmuştur $(\mathrm{t}=-1.15, p<0.05)$. Dördüncü sınıfa devam eden öğrencilerin öz-anlayış puan ortalamaları $(X=75.22)$, birinci sınıfa devam eden öğrencilerin öz- 
anlayış puan ortalamalarından $(\mathrm{X}=70.23)$ anlamlı derecede daha yüksek bulunmuştur $(p<0.05)$.

Üniversite öğrencilerinin öz-anlayış düzeylerinin algılanan anne-baba tutumlarına göre farklılaşıp farklılaşmadığını belirlemek için Kruskal WallisH Testi yapılmıştır. İlgili analizin sonuçları aşağıdaki tabloda yer almaktadır (Tablo 5).

Tablo 5. Öz-Anlayış Düzeylerinin Algılanan Anne-Baba Tutumlarına Göre Farklılaşıp Farklılaşmadığını Belirlemek Üzere Yapılan Kruskal Wallis-H Sonuçları

\begin{tabular}{llccccc}
\hline Puan & Gruplar & N & S.O. & $\mathbf{X}^{\mathbf{2}}$ & sd & $\boldsymbol{p}$ \\
\hline & Demokratik & 117 & 185.12 & & & \\
& Otoriter & 31 & 149.76 & & & \\
Öz- & İlgisiz & 10 & 95.70 & 19.66 & 4 & .001 \\
Anlayış & Koruyucu & 147 & 157.61 & & & \\
& Tutarsiz & 18 & 105.53 & & & \\
& Toplam & 323 & & & & \\
\hline
\end{tabular}

Tablo 5 'te görüldüğü gibi öğrencilerinin öz-anlayış düzeylerinin algılanan anne-baba tutumlarına göre anlamlı düzeyde farklılaşmaktadır $\left(X^{2}=19.66\right.$; $\mathrm{sd}=4 ; p<0.05)$. Farklılaşmanın hangi gruplardan kaynaklandığını belirlemek amacıyla tamamlayıcı karşılaştırma tekniklerine geçilmiştir. Bu amaç için kullanılan özel bir analiz olmadığından ikili karşılaştırmalarda tercih edilen Mann-Whitney-U Testi uygulanmıştır. İlgili testin sonuçları Tablo 6'da verilmiştir.

Tablo 6. Öz-Anlayış Düzeylerinin Algılanan Anne-Baba Tutumlarına Göre Mann-Whitney-U Sonuçları

\begin{tabular}{|c|c|c|c|c|c|c|}
\hline Ölçek & Tutum & $\mathbf{n}$ & Sira Ortalaması & $\mathbf{U}$ & $\mathbf{Z}$ & $p$ \\
\hline \multirow{6}{*}{$\begin{array}{l}\text { Öz- } \\
\text { Anlayış }\end{array}$} & Demokratik & 117 & 66.84 & \multirow{2}{*}{252.50} & \multirow{2}{*}{-2.97} & \multirow{2}{*}{.003} \\
\hline & İlgisiz & 10 & 30.75 & & & \\
\hline & Demokratik & 117 & 145.03 & \multirow{2}{*}{7133.50} & \multirow{2}{*}{-2.37} & \multirow{2}{*}{.017} \\
\hline & Koruyucu & 147 & 122.53 & & & \\
\hline & Demokratik & 117 & 72.44 & \multirow{2}{*}{534.00} & \multirow{2}{*}{-3.36} & \multirow{2}{*}{.001} \\
\hline & Tutarsiz & 18 & 39.17 & & & \\
\hline
\end{tabular}

${ }^{*} p<0.05$.

Tablo 6 incelendiğinde, anne-baba tutumunu demokratik olarak algılayan öğrencilerin öz-anlayış sıra ortalamalarının, anne-baba tutumunu ilgisiz, koruyucu ve tutarsız olarak algılayan öğrencilerin öz-anlayış sıra ortalamalarından anlamlı olarak yüksek olduğu bulunmuştur. 


\section{Tartışma, Sonuç ve Öneriler}

Araştırmanın sonucunda öz-anlayış ile psikolojik katılık arasında olumsuz yönde anlamlı ilişki bulunmuş ve psikolojik katılığın öz-anlayışı negatif yönde anlamlı olarak yordadığı saptanmıştır. Seligowski ve arkadaşları (2015) tarafından yapılan araştırmada da öz-anlayış ile psikolojik katılık arasında olumsuz yönde anlamlı ilişki olduğu bulunmuştur. Ayrıca psikolojik katıllı̆ı̆ın, öz-anlayış korkusunun (fear of self-compassion; kendine anlayış/merhamet göstermeye karşı1 korku ve direnç gösterme) olumsuz etkilerini artırdığı da bulunmuştur (Boykin ve ark., 2018). Öz-anlayışın, psikolojik katılığın tam tersi olan psikolojik esneklik ile olumlu yönde ilişkili olduğu belirtilmiş (Neff ve Tirch, 2013) ve yapılan bir araştırmada öz-anlayış ile psikolojik esneklik arasında olumlu yönde ilişkinin varlığı ortaya koyulmuştur (Marshall ve Brockman, 2016). Öz-anlayışın içsel deneyimlere yargılayıcı olmadan açık olmayı ifade etmesi (Neff, 2003a) ve öz-anlayışı olan bireylerin istenmeyen düşünce ve duyguları bastırma olasılığının daha düşük olması (Leary ve ark., 2007) sebebiyle, öz-anlayış ile psikolojik katılık arasında olumsuz yönde bir ilişkinin olacağı düşünülmektedir (Seligowski ve ark., 2015). Ayrıca psikolojik katılı̆̆ın, kendine karşı yargılayıcı olma, içsel deneyimlerden kaçınma ve psikolojik tepkilere daha fazla önem vermeyi ifade etmesinden dolayı (Bond ve ark., 2011) öz-anlayış üzerinde olumsuz etkisinin var olduğu söylenebilir. Alanyazındaki mevcut çalışmalara göre değerlendirildiğinde bu araştırmada ulaşılan sonucun öngörülebilir olduğu ve diğer çalışmalarla da tutarlı olduğu söylenebilir. Ancak genellenebilirlik açısından, alanda oldukça kısıtlı araştırmalar olması bakımından daha fazla araştırmaya ihtiyaç duyulduğu da açıktır.

Araştırmanın sonucunda öz-anlayış ile bilişsel esneklik arasında olumlu yönde anlamlı ilişkiler bulunmuş ve bilişsel esnekliği öz-anlayışı pozitif yönde anlamlı düzeyde yordadığı saptanmıştır. Öz-anlayışın uyum sağlayıcı işleyişle anlamlı şekilde ilişkili olduğu (Neff, 2004) ve öz-anlayışı yüksek bireylerin olumlu bilişsel yeniden yapılandırmaya büyük ölçüde meyilli oldukları bulunmuştur (Allen ve Leary, 2010). Ayrıca bilişsel esnekliğe sahip kişilerin zorlayıcı ve uyumlu olmayan düşünceler yerine daha dengeli ve uyumlu olan düşüncelere sahip olması, alternatifler üretebilmesi ve zorlayıcı durumları daha başa çıkılabilir görmesi (Gülüm ve Dağ, 2012) sebebiyle ilgili kişilerin aynı zamanda öz-anlayışlarının da yüksek olması beklenebilir. Bu bağlamda değerlendirildiğinde bilişsel esnekliğin de öz-anlayış ile olumlu yönde ilişkili olduğu beklenebilir. Martin ve arkadaşları (2011) tarafından yapılan çalışmada da bilişsel esneklik ile öz-anlayış arasında olumlu yönde anlamlı 
ilişki olduğunu saptamıştır. Ancak ilgili değişkenin öz-anlayış üzerindeki etkilerini inceleyen daha farklı çalışmalara rastlanılmamıştır. Bu araştırmanın sonucu alanyazında ulaşılan benzer araştırmaların sonucu ile tutarlılık göstermiştir. Ancak psikolojik katılık değişkenin de olduğu gibi bilişsel esneklik ile öz-anlayış arasındaki ilişkiyi inceleyen araştırmanın son derece kısıtlı olması açısından bu çalışmanın sonucunun genellenebilirliği açısından yeni çalışmalara ihtiyaç duyulmaktadır.

Cinsiyete göre öz-anlayışın farklılaşıp farklılaşmadığına bakıldığında bu araştırmanın sonucunda anlamlı bir farklılık olmadığı sonucuna varılmıştır. Alanyazın incelendiğinde öz-anlayışın cinsiyet göre farklılaşmadığını bulan araştırmaların (Dilmaç, Deniz ve Deniz, 2009; Neff ve Pommier, 2013) yanı sıra cinsiyete göre farklılığın olduğu sonucuna ulaşan çalışmalar da mevcuttur (Neff, 2003b; Yarnell ve ark., 2015). Alanyazında cinsiyet ile ilgili bulgular değerlendirildiğinde bu araştırmanın bulgusuyla benzer sonuçlara ulaşan ça1ışmaların olmasının yanında farklı sonuçlara ulaşan araştırmalar da bulunmaktadır. Alanyazında cinsiyet açısından ulaşılan sonuçların tutarlılık göstermediği görülmektedir.

Sınıf düzeyine göre öz-anlayışın farklılaşıp farklılaşmadığına bakıldığında bu araştırmanın sonucunda anlamlı bir farklılık olduğu sonucuna varılmıştır. Dördüncü sınıfa devam eden öğrencilerin birinci sınıfa devam eden öğrencilere oranla öz-anlayış düzeyleri anlamlı derecede yüksek olduğu saptanmıştır. Çırpan (2016) tarafından yapılan araştırmada farklı sınıf düzeylerinde öğrenim gören üniversite öğrencilerinin öz-anlayış düzeylerinde anlamlı farklılaşma olmadığı sonucuna ulaşılmıştır. Nazik ve Arslan (2011) tarafından hemşirelik öğrencilerininin öz-anlayış düzeyleri de incelenmiş ve dördüncü sınıfların öz-anlayış puan ortalamalarının birinci sınıflarınkine oranla daha düşük olduğu bulunmuştur. Dilmaç ve arkadaşları (2009) tarafından yapılan araştırmada üçüncü sınıf öğrencilerinin öz-anlayış puan ortalamalarının birinci sınıflardan anlamlı düzeyde yüksek olduğu bulunmuştur. Özyeşil (2001) tarafından yapılan araştırmada da dördüncü sınıfa devam eden üniversite öğrencilerinin birinci sınıfa devam eden öğrencilere göre öz-anlayış düzeyleri anlamlı derecede yüksek olduğu bulunmuştur. Görüldüğü gibi alanyazında araştırmamızın bulgusuyla benzerlik gösteren çalışmaların yanı sıra farklılık gösteren çalışmalar da mevcuttur. Sınıf değişkenine göre alanyazında genel bir tutarlılığın olmadığı görülmektedir. Ancak bu araştırmanın bulgusunda dördüncü sınıfların öz-anlayış düzeylerinin anlamlı düzeyde daha yüksek 
olmasında eğitimin etkili olabileceği ve öğrencilerin ilerleyen yaşlarıyla birlikte olgunlaşmaları sebebiyle de olabileceği düşünülmektedir.

Araştırma sonucunda ayrıca demokratik anne-baba tutumuna sahip öğrencilerin öz-anlayış düzeyleri ile ilgisiz ve tutarsız anne-baba tutumuna sahip öğrencilerin öz-anlayış düzeyleri arasında anlamlı farklılıklar bulunmuştur. Demokratik anne-baba tutumuna sahip öğrencilerin öz-anlayış puan ortalamalarının ilgisiz, koruyucu ve tutarsız anne-baba tutumuna sahip öğrencilerinkine göre daha yüksek olduğu saptanmıştır. Yılmaz ve Kesici (2014) tarafından yapılan bir araştırmada da üniversite öğrencilerinin öz-anlayışları ile demokratik anne-baba tutumu arasında anlamlı ve pozitifi bir ilişki, koruyucu ve otoriter tutum ile anlamlı ve negatif yönde bir ilişki bulunmuştur. Yapılan başka bir araştırmada da demokratik anne-baba tutumuna sahip üniversite öğrencilerinin öz-anlayış puan ortalamaları tutarsız ve koruyucu anne-baba tutumuna sahip olanlardan anlamlı olarak daha yüksek bulunmuştur (Çırpan, 2016). Özyeşil (2011) tarafından yapılan araştırma sonucunda anne-babalarının tutumunu demokratik olarak değerlendiren üniversite öğrencilerinin özanlayış puan ortalamaları anne-babalarının tutumunu değişken, tutarsız, koruyucu ve suçlayıcı ve otoriter olarak değerlendirenlerden anlamlı düzeyde yüksek bulunmuştur. Görüldüğü gibi alanyazında yapılan benzer çalışmalar bu araştırmanın bulgusunu desteklemektedir. Demokratik ebeveyn tutumlarının var olduğu ortamlarda yetişen çocukların duygu ve düşüncelerine saygı duyulur, onlara değer verilir, oldukları gibi kabul edilirler ve yeterli sevgi ve şefkati görürler (Kaya, 1997). Demokratik anne-baba tutumuna sahip aile ortamları güvenli ve destekleyici özelliklere sahip olduğundan öz-anlayışı da geliştirici özelliklere sahip olduğu belirtilmiştir (Neff ve McGhee, 2010).

Öz-anlayışın psikolojik sağlıkla ilişkili olduğu alanyazında bildirilmiştir (Marsahll ve Brockman, 2016; Seligowski ve ark., 2015; Woodruff ve ark., 2014). Öz-anlayışın geliştirilmesinin psikolojik sağlığı da olumlu yönde etkileyeceği açıktır. Sümer (2008) de kişilerin olumsuz duygulardan kurtulması, hayatlarını daha katlanılabilir ve anlaşılabilir duruma getirebilmeleri için özanlayışlarının geliştirilmesi gerekliliğine vurgu yapmıştır. Bu nedenlerle özanlayışı geliştirecek programlar oldukça önemlidir. $\mathrm{Bu}$ araştırma, Türkiye'deki çalışmalarda öz-anlayış üzerindeki etkileri daha önce araştırılmamış olan psikolojik katılık ve bilişsel esneklik değişkenlerinin etkilerini ortaya koyduğu için kuramsal anlamda alana katkı sağlamıştır. Ayrıca, alanda çalışan profesyonellerin, öz-anlayışı artırmaya yönelik yapacakları müdahale 
çalışmalarında da bu araştırmanın sonuçlarından yararlanabilecekleri düşünülmektedir. Araştırmanın bulgularından yola çıkılarak, üniversite öğrencilerinin öz-anlayış düzeylerini artırmak ve geliştirmek için hazırlanacak programlarda psikolojik katılıklarını azaltıcı ve bilişsel esneklik düzeylerini artırıcı çalışmalar yapılabilir. Demokratik ebeveyn tutumu ile öz-anlayış arasındaki olumlu ilişkiden yola çıkılarak ebeveynlerin demokratik anne-baba tutumuna sahip olmaları konusunda anne-babalara yönelik programlar da hazırlanabilir. Ayrıca bu araştırmada yer alan değişkenlerle ilgili başka çalışma olmadığından sonuçların genellenebilirliği açısından yeni çalışmalar yapılabilir.

\section{Kaynakça}

Allen, A. B. ve Leary, M. R. (2010). Self-Compassion, stress and coping. Social and Personality Psychology Compass, 4(2), 107-118.

Anderson, P. (2002). Assessment and development of executive function (EF) during childhood. Child Neuropsychology, 8(2), 71-82.

Bond, F. W., Hayes, S. C., Baer, R. A., Carpenter, K. M., Guenole, N., Orcutt, H. K., Waltz, T. ve Zettle, R. D. (2011). Preliminary psychometric properties of the Acceptance and Action Questionnaire-II: a revised measure of psychological inflexibility and experiential avoidance. Behavior Therapy, 42, 676-688.

Boykin, D. M., Himmerich, S. J., Pinciotti, C. M., Miller, L. M., Miron, L. R. ve Orcutt, H. K. (2018). Barriers to self-compassion for female survivors of childhood maltreatment: The roles of fear of self-compassion and psychological inflexibility. Child Abuse \& Neglect, 76, 216-224.

Büyüköztürk, Ş. (2005). Sosyal bilimler için veri analizi el kitabı (5. baskı). Ankara: Pegem Akademi.

Büyüköztürk, Ş., Kılıı̧-Çakmak, E., Akgün, Ö. E., Karadeniz, Ş. ve Demirel, F. (2015). Bilimsel araştırma yöntemleri (19. baskı). Ankara: Pegem Akademi.

Çırpan, E. (2016). Üniversite ögrrencilerinin duygusal zekâ düzeyleri ve öz-anlayış düzeyleri arasındaki ilişkinin incelenmesi. Yayımlanmamış yüksek lisans tezi, İstanbul Arel Üniversitesi Sosyal Bilimler Enstitüsü.

Deniz, M. E., Kesici Ş. ve Sümer, A. S. (2008). The validity and reliability study of the Turkish version of self-compassion scale. Social Behavior and Personality, 36(9), 1151-1160.

Dennis, J. P. ve Vander Wal, J. S. (2010). The cognitive flexibility inventory: Instrument development and estimates of reliability and validity. Cognitive Therapy and Research, 34(3), 241-253.

Dilmaç, B., Deniz, M. ve Deniz, M. E. (2009). Üniversite öğrencilerinin öz-anlayışları ile değer tercihlerinin incelenmesi. Değerler Eğitimi Dergisi, 7(18), 9-24.

Eslinger, P. J. ve Grattan, L. M. (1993). Frontal lobe and frontal-striatal substrates for different forms of human cognitive flexibility. Neuropsychologia, 31(1), 1728.

Gülüm, I. V. ve Dağ, İ. (2012). Tekrarlayıcı Düşünme Ölçeği ve Bilişsel Esneklik Envanterinin Türkçeye uyarlanması, geçerliliği ve güvenilirliği. Anatolian Journal of Psychiatry, 13(3), 216-223. 
Hollis-Walker, L. ve Colosimo, K. (2011). Mindfulness, self-compassion, and happiness in non-meditators: A theoretical and empirical examination. Personality and Individual Differences, 50, 222-227.

Kaya, M. (1997). Ailede anne-baba tutumlarının çocuğun kişilik ve benlik gelişimindeki rolü. Ondokuz Mayıs Üniversitesi Illahiyat Fakültesi Dergisi, 9(9), 193204.

Leary, M. R., Tate, E. B., Adams, C. E., Allen, A. B. ve Hancock, J. (2007). Selfcompassion and reactions to unpleasant self-relevant events: the implications of treating oneself kindly. Journal of Personality and Social Psychology, 92(5), 887-904.

Marshall, E. J. ve Brockman, R. N. (2016). The relationships between psychological flexibility, self-compassion, and emotional well-being. Journal of Cognitive Psychotherapy, 30(1), 60-72.

Martin, M. M., Staggers, S. M. ve Anderson, C. M. (2011). The relationships between cognitive flexibility with dogmatism, intellectual flexibility, preference for consistency, and self-compassion. Communication Research Reports, 28(3), 275-280.

Nazik, E. ve Arslan, S. (2011). Hemşirelik öğrencilerinin empatik becerileri ile öz duyarlıkları arasındaki ilişkinin incelenmesi. Anadolu Hemşirelik ve Sağlık Bilimleri Dergisi, 14(4), 69-75.

Neff, K. D. (2003a). Self-compassion: An alternative conceptualization of a healthy attitude to ward oneself. Self and Identity, 2(2), 85-102.

Neff, K. D. (2003b). The development and validation of a scale to measure self- compassion. Self and Identity, 2(3), 223-250.

Neff, K. (2004). Self-compassion and psychological well-being. Constructivism in the human sciences, 9(2), 27-37.

Neff, K. D., Kirkpatrick, K. L. ve Rude, S. S. (2007). Self-compassion and adaptive psychological functioning. Journal of Research in Personality, 41(1), 139-154.

Neff, K. D. ve McGhee, P. (2010). Self-compassion and psychological resilence among adolescents and young adults. Self and Identity, 9, 225-240.

Neff, K. D. ve Pommier, E. (2013). The relationship between self-compassion and other-focused concern among college undergraduates, community adults, and practicing meditators. Self and Identity, 12(2), 160-176.

Neff, K. ve Tirch, D. (2013). Self-compassion and ACT. T.B. Kashdan ve J. Ciarrochi, (Eds.), Mindfulness, acceptance, and positive psychology: The seven foundations of well-being içinde (78-106). Oakland, CA: Context Press/New Harbinger Publications.

Özyeşil, Z. (2011). Üniversite ögrencilerinin öz-anlayış düzeylerinin bilinçli farkındalık kişilik özellikleri ve bazı değişkenler açısından incelenmesi. Yayımlanmamış doktora tezi, Selçuk Üniversitesi Eğitim Bilimleri Enstitüsü.

Seligowski, A. V., Miron, L. R. ve Orcutt, H. K. (2015). Relations among self-compassion, PTSD symptoms, and psychological health in a trauma-exposed sample. Mindfulness, 6(5), 1033-1041.

Shapira, L. B. ve Mongrain, M. (2010). The benefits of self-compassion and optimism exercises for individuals vulnerable to depression. The Journal of Positive Psychology, 5, 377-389. 
Smeets, E., Neff, K., Alberts, H. ve Peters, M. (2014). Meeting suffering with kindness: effects of a brief self-compassion intervention for female college students. Journal of Clinical Psychology, 70(9), 794-807.

Stöber, J. (2003). Self-pity: Exploring the links to personality, control beliefs, and anger. Journal of Personality, 71(2), 183-220.

Sümer, A. S. (2008). Farklı öz-anlaylş (self-compassion) düzeylerine sahip üniversite ögrencilerinde depresyon anksiyete ve stresin değerlendirilmesi. Yayımlanmamış yüksek lisans tezi, Selçuk Üniversitesi Sosyal Bilimler Enstitüsü.

Woodruff, S. C., Glass, C. R., Arnkoff, D. B., Crowley, K. J., Hindman, R. K. ve Hirschhorn, E. W. (2014). Comparing self-compassion, mindfulness, and psychological inflexibility as predictors of psychological health. Mindfulness, 5(4), 410-421.

Yarnell, L. M., Stafford, R. E., Neff, K. D., Reilly, E. D., Knox, M. C. ve Mullarkey, M. (2015). Meta-analysis of gender differences in self-compassion. Self and Identity, 14(5), 499-520.

Yavuz, K. F. (2015). Kabul ve kararlılık terapisi (ACT): genel bir bakış. Türkiye Klinikleri Journal of Psychiatry Special Topics, 8(2), 21-27.

Yavuz, F., Ulusoy, S., Işkın, M., Esen, F. B., Burhan, H. S., Karadere, M. E. ve Yavuz, N. (2016). Turkish version of Acceptance and Action Questionnaire-II (AAQII): A reliability and validity analysis in clinical and non-clinical samples. Bulletin of Clinical Psychopharmacology, 26(4), 397-408.

Yılmaz, M. T. ve Kesici, Ş. (2014). Anne baba tutumları ve kardeş sırasının üniversite öğrencilerinin öz-anlayışlarının gelişimine etkisi. OPUS Uluslararası Toplum Araştırmaları Dergisi, 4(6), 131-157. 